\title{
Estéticas y Políticas del Nazismo
}

\author{
Jordi Claramonte Arrufat* \\ Aesthetics and Nazi Politics
}

\begin{abstract}
RESUMEN:
Cuando se alude a las Estéticas características del Nazismo, solemos empezar por pensar en grandes desfiles, encuentros de la juventud, marchas de antorchas, masivos sermones al aire libre y multitudes enardecidas dispuestas a lanzarse a degüello sobre el enemigo más próximo. Sin embargo no es eso lo que se desprende en absoluto, ni de un análisis de los materiales y prácticas, ni del estudio de los textos y declaraciones de los principales responsables de la producción estética del nazismo.
\end{abstract}

Veremos en este artículo, por el contrario, que la apuesta de la inmensa mayoría de la producción estética nazi estuvo vinculada a la producción y estabilización de ciudadanos tan normales y razonables como nos sea dado concebir hoy mismo.

PALABRAS CLAVE

Nazis, normalidad, masas

\begin{abstract}
When we come to the issue of typically nazi aesthetics, you can expect to have in mind dreadful images of big parades, youth meetings, massive speeches in the open air and fanatic multitudes willing to assault and destroy any enema at close range. Unfortunately that's not the pattern we obtain out of the analyses either of the aesthetic practices and materials or the texts and statements made by the main responsible agents of nazi aesthetic production.
\end{abstract}

We shall see along this article how most of the nazi aesthetic outcomes were closely related to the production and stabilization of such normal and sensible citizens as we might be able to conceive of.

\section{KEYWORDS}

Nazis, normalcy, masses

\section{ESTÉTICAS Y POLÍTICAS DEL NAZISMO}

Cuando se alude a las Estéticas fascistas o a las características del Nazismo u otros regímenes totalitarios, solemos empezar por pensar en grandes desfiles, encuentros de la juventud, marchas de antorchas, masivos sermones al aire libre y multitudes enardecidas dispuestas a lanzarse a degüello sobre el enemigo más próximo.

\footnotetext{
* Facultad de Filosofía, UNED. c/ Senda del Rey 7, Despacho 310. 28040 Madrid. jclaramonte@fsof.uned.es
} 
Que las estéticas fascistas en general susciten semejante asociación de ideas no es en absoluto extraño puesto que, no sin cierta razón, el término «fascismo» suele ligarse a la capacidad de encuadramiento y movilización de los elementos más violentos e irracionales de nuestro comportamiento.

En el cumplimiento de esa asimilación se le suelen atribuir no pocos, ni poco misteriosos, poderes a la estética de los fascismos. La estética parecería aquí ser la encargada de informar una propaganda total, una suerte de monopolio de las representaciones que permitiría modelar la consciencia de las masas, nada menos.

En lo que sigue vamos a intentar elucidar qué bases históricas permiten defender semejante función para la estética, al menos en el caso del nacionalsocialismo alemán entre 1934 y 1945, quizá el régimen fascista cuyos niveles de eficacia siempre dan en destacarse. Esperamos poder demostrar que no resulta sostenible, ni oportuno, atribuirle unos poderes casi mágicos ni al arte ni tampoco a la propaganda del fascismo. Veremos, en cambio, cómo hay otros elementos de organización de la sensibilidad y la agencialidad que quizás han recibido menos atención y que a nosotros, como investigadores de la estética y la teoría de las artes, pueden sernos del mayor interés.

Podemos entrar en materia, tomando como base de partida un texto clásico en lo que a «idees reçues» sobre fascismo y arte fascista refiere. A mediados de los años 50, en plena guerra fría, y en pleno auge del movimiento intelectual que tuvo que construir el concepto de totalitarismo, publicaba Werner Haftmann su obra de referencia «Malerei im 20 Jahrhundert», del que escogemos este breve párrafo, en el que definía el arte totalitario como:

«... el fenómeno de unidad estilística presente en todas las dictaduras. Así como éstas, para fundar su propia potencia proceden a la movilización de las masas y a destruir el libre espíritu individual, del mismo modo el arte totalitario como norma vinculante adopta el tipo medio de la mentalidad de la gran masa y elimina lo particular. El contenido y su importancia propagandística son los elementos prioritarios, adecuado a los hábitos visuales de la masa... En su más intima esencia el principio totalitario tiende a la aniquilación de la fe en el valor personal y en la función del espíritu aislado.»1

Se juntan en este texto una serie de ideas fuerza que por mucho que hayan tenido un papel constante y necesario en la legitimación de las democracias occidentales, especialmente como hemos dicho a lo largo de la década de los 50, resultan ahora difícilmente sostenibles tanto desde un punto de vista estrictamente estético como desde una más amplia visión histórica y política. Ahora que el enemigo totalitario soviético se ha reconvertido a mundo libre, y el principal arte que allí se produce acaso sea el que sus habitantes han de poner en juego para sobrevivir, quizás sea tiempo de analizar más comedidamente la base histórica y estética de algunos

1 HAFTMANN, Werner : «Malerei im 20 Jahrhundert», Manchen, Prestel Verlag,, 1954, página 425. 
de los enunciados presentes en el discurso clásico sobre el totalitarismo y que se dejan ver con toda claridad en el breve párrafo que nos ha servido de aperitivo.

Yendo pues a por los términos a los que recurre Haftmann en el modélico párrafo citado, no cabe sino empezar contraviniendo el principio del mismo, dejando claro que el arte fascista no parece mostrar una especial unidad estilística ni tan siquiera una manifiesta ruptura respecto al corpus del arte «burgués» del siglo XIX: como hacía notar con orgullo la presidenta de la Asociación de Arte Alemán de Karlsruhe, la Sra Feistel-Rohmeder, su asociación había mantenido firmemente durante quince años y sin la mas mínima desviación, la línea señalada como válida por la dirección artística del Tercer Reich, antes siquiera que dicha línea hubiera sido definida o que Hitler llegara al poder ... en ese sentido sostiene Bertold Hinz:

" después de la toma del poder no se había simplemente introducido un "nuevo" arte, sino que ya desde hacía mucho tiempo existían dos tipos de arte en Alemania; el arte moderno era quizá el dominante pero ciertamente no el único...»².

El arte fascista parece por tanto entroncar de un modo relativamente aproblemático con una línea de producción artística perfectamente aceptada y a la búsqueda de hegemonía en la Alemania de los años 30, así como en el resto de Europa y Estados Unidos. Que esta producción artística tuviera un cierto carácter kitsch no es extraño si aceptamos las tesis de Hermann Broch, que vinculan el kitsch precisamente con el recurso obsesivo a usar vocablos ya aceptados, impulsados por la necesidad —vileza ética diría Broch ${ }^{3}$ — de agradar e impresionar sin salirse de la raya, ni arriesgarse en lo más mínimo... sin duda es difícil sostener que dichas limitaciones formales sean inherentes de modo exclusivo o distintivas siquiera del arte fascista. En otras palabras los elementos de un clasicismo decorativo y pompier, tan correcto como estéril y algo kitsch ya estaban instalados en la cultura estética europea desde finales del XIX. El fascismo acabó encontrando más oportuno acoplarse con ellos, sin perjuicio de que tanto en Italia como en Alemania e incluso en España hubiera sus momentos de flirteo con algunos artistas de la vanguardia — de Marinetti a Nolde o Jimenez Caballero, pero ello no le otorga una nueva ni una mayor unidad estilística a la producción artística de esa tendencia...

Tampoco puede sostenerse que una vez orientado el fascismo hacia el campo del arte academicista, éste haya destacado por una clara decantación hacia el contenidismo y la propaganda, dentro mismo del campo del arte y la pintura culta, que es, por lo demás, a lo que se refiere Haftmann en el texto arriba citado. Esta opinión se hace difícil de sostener si recurrimos a los datos que nos proporcionan investigaciones ya clásicas como la que presentara en su día Hildegard Brenner ${ }^{4}$ de-

2 HINZ, Berthold: Arte e Ideología del Nazismo, Valencia, Fdo. Torres editor, 1978, pág. 136

3 BROCH, Hermann, «Kitsch, vanguardia y el arte por el arte, Barcelona, Tusquets, 1970

4 BRENNER, Hildegard, Die Kunstpolitik des Nationalsozialismus, Hamburg, Rowohlt, 1963; así como en HOLBORN, Hajo 'Art in the Political Power Struggle of 1933 and 1934', en Republic to Reich: The Making of the Nazi Revolution, New York, Pantheon, 1972 pp. 394-432. 
mostrando cómo las obras seleccionadas en las «Grandes exposiciones de Arte Alemán», como la de 1937 correspondían a los siguientes géneros: paisajes (40\%), «mundo masculino y mundo femenino» (campesinos, deportistas, juventud - $20 \%$ ), retratos $\left(15{ }^{\prime} 5 \%\right.$ ) animales $(10 \%)$ oficios $(7 \%)$... El único signo del Tercer Reich, dice Brenner, son los retratos de funcionarios (1'5\%) y los de edificios del regimen (1"7\%). Como ha destacado Joan Clinefelter en su más reciente estudio Artists for the Reich lo que se ha dado en llamar Arte nazi se define menos por el contenido y el estilo que por la glosa interpretativa que se le superpone ${ }^{5}$.

Si el arte nazi no tuvo una especial unidad estilística, ni desde su falta de sentido de conjunto se orientó de modo irrefutable hacia la propaganda, entonces quizá haya que cambiar de foco y pensar que acaso los misteriosos poderes de la estética en los fascismos haya que buscarlos en las prácticas menos elevadas, aquellas correspondientes a la pura propaganda y los medios de masas, con sus escenografías, sus discursos y todo su aparato de movilización...

El caso es que trabajando sobre los datos correspondientes a la organización de grandes actos de masas y comparando su peso especifico en los primeros tiempos del régimen nazi y sus años de plenitud criminal, belicista y de catástrofe final, sorprende encontrarse cómo los análisis más recientes vienen a sostener que:

"Los rituales y organizaciones de masas, las campañas etc... sólo eran capaces de crear estados de animo maníacos e intoxicados durante periodos más y más breves frente a los desafíos que el régimen debía asumir... Por demás que muchos ingredientes eran precisos para un acto de masas exitoso y su efectividad era siempre limitada...De hecho estas grandes ceremonias con sus trucos limitados empezaron a ser menos frecuentes (aunque nunca desaparecerían del todo) a partir del $35{ }^{6}$.

Es también en el año 35 (tan solo un año después del acceso al poder de Hitler) cuando se empiezan a recortar las emisiones radiofónicas dedicadas a transmitir los famosos discursos del Führer, pasando estas emisiones de contar con una frecuencia prácticamente diaria, a una única emisión por semana, para desaparecer casi del todo en un periodo tan temprano como el año 38.

¿Es ese el medio de propaganda total, que debía exorcizar a las masas? ¿aquel en el que se basaba el nazismo para inducir una intoxicación colectiva en millones de personas?

Por supuesto que, de modo distintivo el régimen nazi contaba con un Ministerio de Propaganda, al cargo del cual se encontraba el mismísimo Goebbels, pero si este ministro merece algún crédito como buen propagandista, será precisamente no por saturar de discursos incendiarios y de retórica fácilmente desarticulable la

5 CLINEFELTER, Joan, Artists for the Reich: Culture and Race from Weimar to Nazi Germany. Oxford, Berg, 2005, pp. 3-4

6 PEUKERT, Detlev, pág. 188 
esfera pública sino porque se dará cuenta, relativamente pronto, que no se puede aspirar a generar y mucho menos a controlar, en una sociedad compleja y moderna como era la alemana de los años 30, un clima de opinión perfectamente homogéneo. Uno de los mayores hallazgos y quizás de los más consensuados actualmente entre los investigadores del fascismo histórico, es que la forma más correcta de describir la tanto la atmósfera ideológica como el funcionamiento mismo del poder, no es tanto la de una absoluta centralización y homogeneidad como la de una poliarquía que basará su estabilidad en el equilibrio entre un número relativamente alto de discursos y fuentes de poder. El Führer mismo logrará sobrevivir a base de aprovechar y canalizar los enfrentamientos y rivalidades entre las diversas líneas que se componen en el aparato de gobierno y guerra nazi: el aparato militar e industrial de las SS de Himmler entrará en tensión con figuras como Goering que cuenta con el apoyo de la Luftwaffe o como Speer que canalizará las influencias de la gran industria metalúrgica y armamentística...

En el plano ideológico y propagandístico las mismas variaciones de la guerra y la hegemonía relativa de los diferentes sectores del partido y el ejército hicieron que los énfasis tuvieran que pasar de atacar al liberalismo inglés a meterse con el totalitarismo soviético, ensalzar la alianza con los italianos y los japoneses o ignorarla por completo...

Un dato bien relevante sobre la categoría como propagandista de Goebbels es que ni siquiera perdió esfuerzos en intentar reproducir el ambiente de entusiasmo colectivo que despertó el inicio de la guerra en el año 1914: ni en el 39, ni tan siquiera con la toma de París, se producirán manifestaciones de gozo popular como las que se habían visto en los comienzos de la Primera Guerra Mundial. Goebbels sabe que puede jugar con tendencias e ideas que están de alguna manera presentes en la sociedad alemana, pero crearlas de cero excede sus posibilidades y él -a diferencia de muchos de los que han escrito sobre él- lo sabe.

La estrategia del flamante ministro de propaganda será, muy por el contrario, la de disponer que el ministerio de propaganda apoye la producción de sano entretenimiento apolítico, relajante para la dura vida de la gente en la retaguardia, tanto mas dura en tanto se vaya agravando el aislamiento del régimen y la marcha de la propia situación bélica. Esta es por lo demás una constante bien comprensible en las situaciones de ansiedad y stress, como las producidas por la guerra o la producción. Como destacaba un corresponsal del New York Times en 1943: «Los soldados quieren música, quieren reírse, ser entretenidos. No quieren dramáticas imágenes de guerra...»7.

$Y$ hay que tener en cuenta que en la segunda guerra mundial, sobre todo en la Alemania sometida a los bombardeos extensivos, el frente y sus estados de animo

7 «The soldiers want music, they want to laugh, they want to be entertained. They do not want dramatic war pictures...» «5th Army Troops Want More Films,» New York Times, November 19, $1943,6$. 
llegaba de lleno hasta la misma retaguardia, sometida a esfuerzos y tensiones a menudo comparables con las de los soldados de primera línea.

Los datos sobre la producción de cine en Alemania, quizá el entretenimiento de masas por excelencia, son bien iluminadores al respecto de lo que aquí sostenemos: como Richard Grünberger demuestra en su monumental «Historia Social del Tercer Reich», de los 1100 largometrajes filmados más de la mitad eran historias de amor o comedias, una cuarta parte cintas policíacas, de aventuras o musicales. El veinticinco por cien restante lo formaban en partes más o menos iguales películas de temática histórica, militar, juvenil y política. Por eso podemos sostener con este autor que «en ningún arte se mantuvo tanto una continuidad después de 1933 como en el cine... gobernantes y gobernados llegaron así a un acuerdo acerca de la función primordial del cine: facilitar el Wirklichkeitsflucht, la huida de la realidad»8.

También coinciden en este sentido los datos procedentes de las producciones musicales: estilísticamente hablando los nuevos productos musicales de los media abrazaban el idilismo rural-folk, las marchas de metales, versiones "sentimentalizadas" de las grandes obras de concierto y opera, valses de ensueño de las películas UFA, etc...

Podemos concluir de estos datos que, como dice Detlev Peukert, uno de los principales actores del cambio de paradigma en la investigación del carácter y peculiaridades del nazismo:

«En el ministerio de Goebbels se dieron cuenta pronto de que una lealtad duradera, capaz de sobrellevar los problemas cotidianos no podía en modo alguno ser generada sólo por ceremonias de solsticio. El único modo de remedar la falta de sustancia de la Volkgemeinschaft era producir «lealtad pasiva», y esta dependía más de que los media ofrecieran entretenimiento y distracción»? ${ }^{\text {. }}$

Por supuesto que dicha apuesta por el entretenimiento apolítico comparecía acompañada por el pronunciamiento de Goebbels que sostenía que el lugar de las SA estaba en la calle y no en la pantalla de cine. Y ahí es donde queremos llegar: la especificidad de los fascismos no debe buscarse tanto en factores de orden estético, como en los muy diferenciados rasgos políticos y militares que conducirán a una guerra como la del frente del este, donde se violarán todas las convenciones y los usos militares comunes o a persecuciones como las sufridas por la oposición política, los gitanos o los judíos en toda Europa.

Parece entonces que si nos preocupa el funcionamiento de las estéticas en el fascismo, deberemos dirigir nuestra atención más a su funcionamiento en tanto generadoras de consenso e «indiferencia», que no a grandes y siempre peligrosas movilizaciones de masas.

8 GRÜNBEGER, Richard, «Historia Social del Tercer Reich», Barcelona, Destino, 1976, pág. 397

9 PEUKERT, Detlev, op.cit. pág. 163 
Parecería que las palabras clave para «explicar» el funcionamiento cotidiano del fascismo podrían andar más cerca de las relativas a normalidad, buen gusto, armonía, etc...

No puede suponer esto una negación de la especificidad del fascismo, ni el enésimo intento de estirar la definición de los regímenes fascistas hasta hacerlos irreconocibles. Más bien al contrario, se trata de ver algo que acaso estábamos pasando por alto: las continuidades que se dan en un plano estético y las rupturas que efectivamente se dan en un plano militar y político y que por falta de estudio han podido seguir el camino abierto sin mayor problematización.

Como ya hemos adelantado, buena parte de los relatos sobre el fascismo realizados a la sombra de la Guerra Fría y en función de los enfoques totalitaristas e intencionalistas, dieron en construir una imagen tal de los regímenes fascistas que hubiera resultado del todo insostenible de no poder recurrir a algún misterioso componente, la estética, capaz de explicar el apoyo continuado de un porcentaje tan alto de la población, incluso en las condiciones desesperadas de los últimos años de la guerra. Sólo la estética podía hacer, en dichas teorías, el papelón de explicar ese apoyo sin tener que reconocer de un modo u otro los tan innegables como suicidas logros en el plano económico y militar. Algo nuevo del nazismo será seguramente la vinculación del crecimiento económico a las grandes obras públicas y a la generación de grandes conglomerados industriales, militares y tecnológicos, a cuyo calor se acabará con el desempleo y se logrará una base y una legitimidad social sin precedentes. El fascismo demuestra la viabilidad de esa receta, así como su necesario acompañamiento de las guerras y la proliferación armamentística necesarias para mantener en pie semejantes conglomerados. A su vez la disciplina productiva y bélica conllevará extremar los procesos de normalización y supresión de grupos percibidos como asociales o disruptivos.

Cabe recordar a este respecto que en la Alemania posterior a 1934 la estabilización de la situación económica dio asiento a una clase obrera relativamente acomodada que buscó en el cine y la radio una nueva dimensión de la esfera pública en la que encontrar fundamentalmente elementos de entretenimiento y consenso. Asimismo el creciente rol del turismo de masas y la promesa de acceso generalizado al automóvil contribuyeron no poco a la estabilidad del dominio nazi, como el mismo Hitler tuvo ocasión de reconocer abiertamente en repetidas ocasiones ${ }^{10}$.

Todo esto será en los años 30 altamente característico de los regímenes como el nazi, marcando una cierta ruptura con el estilo de vida de Weimar, e introduciendo una innegable especificidad. Ahora bien, una vez explorado el modelo, para nada este quedará restringido a Alemania.

Si consideramos los patrones de consumo, de filiación y persecución política desde los aparatos del estado y de implicación bélica de la América de los años

10 GRÜNBEGER, Richard, op.cit. pág. 399 
50 , veremos como éstos ofrecen muchas continuidades interesantes. Nos encontramos ahí con la consecución de niveles elevados de consumo comparecieron vinculados a una política exterior y militar agresiva —de América Latina a Corea- y a una persecución relativamente abierta de la disidencia política, dotada de claros sesgos de discriminación racial y antibolchevismo, como pudo verse en los asesinatos y persecuciones de los luchadores por los derechos civiles o las listas negras del maccarthismo. Rasgos todos que si bien no permiten, en ningún caso, considerar a la sociedad americana de los años 50 como si de una sociedad fascista se tratara, tampoco hacen demasiado fácil una caracterización social, militar y política del fascismo... con la que se hubieran hallado — sin duda- demasiadas coincidencias como para dar cuenta cómodamente de las especificidades del fascismo.

De esta aseveración habrá que sacar consecuencias considerando, para empezar, que no es fácil postular ninguna subjetividad radicalmente nueva o excepcional que sirva de base y apoyo al fascismo. $Y$ desde luego no hay ninguna gran operación de alta taumaturgia estético-propagandística capaz de explicar por sí misma las grandes transformaciones industriales, militares y políticas tramadas bajo la cobertura de los fascismos. Por el contrario, todas las pistas apuntarán a hacernos pensar en el equilibrio característico del ciudadano fascista, la proporción entre movimiento y reposo, entre entretenimiento e inopia, entre producción y guerra... . Veamos cómo dicho equilibrio ha tenido sus continuidades después de la segunda guerra mundial en el seno de los regímenes del capitalismo fordista.

\section{EL LARGO CAMINO DE CONSTRUCCIÓN DE LA NORMALIDAD.}

Cabría, antes de nada, preguntarse en qué consiste movilizar una masa, o más bien, en qué se diferencia de movilizar a una cantidad de individuos, o mejor aun, de conseguir que una cantidad crítica de éstos se abstenga, por miedo o por falta de cauces, de intervenir, oponerse o eludir, las decisiones de los grupos de poder.

¿Se ha de asumir que el fenómeno político fundamental en las sociedades industriales modernas, esa especie de (des)movilización-de-masas coincide plena y llanamente con la destrucción del libre espiritu individual, como parecen pensar autores como Haftmann o el mismo Wilhelm Reich?

¿Será del todo una casualidad que las primeras «movilizaciones de masas», en los ejércitos con levas generalizadas, por ejemplo, coincidan con la concesión a los individuos de sus derechos y su dignidad de ciudadanos por las administraciones «revolucionarias» y napoleónicas? No en balde fueron estas administraciones las que impusieron elementos que, desde la numeración de las casas en las calles a los sistemas de higiene social, contribuyeron decisivamente a optimizar el 
encuadramiento individualizado de la población, facilitando así enormemente su movilización personalizada para la producción o la guerra...

Foucault ha mostrado con todo detalle cómo la evolución característica de la sociedad occidental hacia un orden político propiamente moderno se ha centrado en la producción y extensión de normalidad, de una serie de patrones conductuales y estéticos que han tenido un papel fundamental como herramienta de control político. Siguiendo las ideas apuntadas por Foucault podría sostenerse que lo primario para la movilización, o mucho mejor para que no pueda suscitarse oposición a ella, parece ser la partición de la masa, o si se prefiere la «fragmentación de la multitud», de lo indiferenciado, en individuos responsabilizables, localizables, culpabilizables y tanto más expuestos cuanto más designables. En el caso del fascismo además, parece claro que lo que se realiza es una partición en individuos cansados pero con un nivel adquisitivo superior al acostumbrado y con ganas de distraerse.

Lo mismo habría que puntualizar respecto a lo de la «aniquilación de la fe en el valor personal» también enunciado por Haftmann. Justo si en algo se distinguen, precisamente, los fascismos es por la «re-dignificación» del valor de la nación (frente a la Republica de Weimar y la maltratada Italia de post-guerra) pero también del ciudadano individual - siempre y cuando sea miembro del club de la raza elegida claro está - al que se le ofrecen posibilidades de integración, de progreso personal y de responsabilidad en las múltiples organizaciones del partido. No se le ofrece democracia directa, ni capacidad alguna de intervención o decisión real, como tampoco lo hacen los regímenes burgueses, pero si que obtiene una sensación de continuado progreso y de mejora de sus posibilidades de vida. Otra cuestión es el grado en que semejante progreso esté directamente basado en el expolio sistemático de países enteros o que sea del todo insostenible... extremo este del que quizá nosotros mismos deberíamos poder decir algo. El programa de legitimación, la estética de la normalidad que reproduce el nazismo con cierta consistencia, podría describirse, para decirlo en los términos de los tour-operadores, como una especie de «inclusive-exclusive resort».Todo está incluido, mientras el grupo esté bien definido.

Aunque hablemos de turismo, o deportaciones de masas nunca insistiremos bastante en el hecho de que todos esos movimientos se dan tras un cuidadoso proceso de individuación. Contra todo lo que se ha dicho tantas veces, es importante tener presente que el fascismo no anula la individualidad de la gente, al contrario, más bien la hincha y no tanto con discursos belicistas y patrioteros, con discursos del Führer, como con ilusiones de ahorro, viajes de ensueño y, como ya hemos adelantado, automóviles

11 Es interesante a este respecto revisar investigaciones como la del articulo de en que se ponen de relieve la similitud de patrones de conducta y de efectos económicos del turismo de masas y la ocupación militar en países como Dinamarca, Suecia o los Países Bajos. Puede verse a este respecto BESSEL, Richard, Life in the Third Reich, Oxford, Oxford University Press, 2001. 
Semejante plan de «dignificación» se desplegaba por tanto en dos planos: el de las vidas personales de los ciudadanos y el de la Nación. El turismo y la guerra ${ }^{11}$, los vehículos familiares y los panzers son la cara y la cruz de la moneda del fascismo. Por eso, no es de extrañar que aun hoy en las entrevistas e «historias de vida» obtenidas de antiguos ciudadanos del Tercer Reich siga apareciendo un discreto apego al régimen «pese a todo».

Aunque la mayoría de los alemanes no pudieran permitirse acceder a los cruceros que, ya por entonces, empezaban a dirigirse a Turquía o Canarias, siempre quedaban los viajes de fin de semana a zonas más cercanas o las vacaciones en el campo... los nazis inventaron el turismo de masas, que tuvo su versión civil con Kraft durch Freude, la gran organización de ocio del régimen, su versión militar con las extensas zonas ocupadas desde Francia al Caucaso y su versión infrahumana con la obsesión por mover enormes cantidades de cuerpos antes de proceder a su extrema explotación o su liquidación.

Los informes del partido socialdemócrata en la clandestinidad dan prolijos detalles de cómo la antaño aguerrida clase obrera alemana empezó muy pronto a pillarle el gusto a esta vida disciplinada que permitía ahorrar y tener acceso a niveles de consumo poco habituales hasta entonces.

No en vano nos encontramos en la época de aparición en Europa de lo que Henry Ford ya había empezado a generalizar en los EEUU: el acceso al utilitario. Los trabajadores alemanes no sólo obtienen trabajo y una relativa estabilidad (otra cosa serán los derechos laborales) sino que obtienen sobre todo la trama de ilusiones que supone el ahorro, el ir pagando los bonos que en un plazo determinado le darán acceso a un automóvil: el Kdf Wagen (Kraft durch Freude, de nuevo, es decir, Energía a través de la alegría, algo así como el pensamiento positivo hecho institución nazi) precedente directo en diseño y lugar social del Volkswagen o Coche del Pueblo o la Gente.

El proyecto antropológico que las estéticas fascistas parecen implicadas en llevar adelante no es ni el del ciudadano embrujado, de voluntad anulada por el estado omnipresente, ni el fanático continuamente dispuesto a la guerra y al exterminio (ambas figuras, si leemos ahora a autores como Wilhelm Reich, tienen más de fantoche, que de posibilidad humana sostenible).

El proyecto humano de las estéticas fascistas es nada menos que el del «ciudadano normal» el del buen chico, dotado de sentido común, y capaz de ser disciplinado y ahorrativo porque así le conviene y nada se puede hacer para cambiarlo.

Ya Musil había profetizado, por cierto, que ese convencimiento de que «el estado definitivo de un hombre espiritualmente instruido era poco más o menos la limitación, la «especialidad» unida al convencimiento de que todo debía cambiar; sin embargo era inútil reflexionar sobre ello..». El ciudadano instruido, el ciudadano que lee los periódicos, que se reconoce en la opinión pública... que prefiere no hablar de política... 
Así parece que lo siniestro de las estéticas fascistas no estará tanto en los grandes movimientos de masas, como en los consensos «individuales».

La diferencia es importante porque es en base a ella que el trabajo estético relevante del fascismo no está tanto en una tramoya de la excepción como en la horticultura de la «normalidad», no tanto en vistosos aquelarres de masas, como en pacíficos paisajes y bodegones para el salón de quien quiere asegurarse de quedar del lado de la zanja de que hay que estar.

Las estéticas fascistas serán entonces los dispositivos que cultivan y amarran esa indiferencia, esa «normalidad»... 
